soldiers training. No adaptation of nesting habits to war-time changes has been reported that equals the resourcefulness of the sand-martins that nested in a trench dug for military training near Gidea Park Station in 1917.

\section{OBSERVATIONS FOR THE CAPE ASTROGRAPHIC ZONE}

$\mathrm{T}$ HE work which the Royal Observatory, Cape of Good Hope, undertook on the Astrographic Zones $-40^{\circ}$ to $-52^{\circ}$ has been completed and is now available in the volume referred to below*. It was felt that the value of the work would be greatly increased if the spectral types were also given and accordingly these were entered in the copy for the Press from the Henry Draper Catalogue. Owing to the faintness of the stars, however, spectral types were available for only a very limited number, about a quarter of the stars being available.

Dr. Shapley, of Harvard Observatory, agreed that this work was of great importance and the late Miss Cannon undertook the responsibility for it. Unfortunately, the identification of the stars by their Right Ascension and Declination proved too laborious, but the method finally adopted was highly successful. The positions of the stars in a region of the sky photographed by Dr. Shapley having bəen calculated from rectangular co-ordinates, it was possible by means of the latter to identify the stars on the Astrographic plates by the réseau. It is highly creditable that the spectral types of nearly 90 per cent of the stars were determined and at the same time the spectral types of most of the outstanding stars of the Zone Catalogue. The latter appear as an appendix.

Altogether fifteen tables are given in the volume, and a full explanation accompanies each of these. Under Magnitudes, Table 1 compares the magnitudes in various catalogues with the Cape mean photographic magnitudes. The basis of the system for the "Cape Magnitudes" is explained at the beginning of this section. A sequence of 71 stars from mag. 5 to mag. 12 was selected in the neighbourhood of the South Pole, and an accurate photographic scale was established among these stars by means of a diffraction grating and a series of exposures ranging from 3 sec. to $30 \mathrm{~min}$. The zero point of each plate was based on the Harvard visual magnitude of the brightest star, $\sigma$ Octantis, mag. $5 \cdot 48$, corrected for the type $F 0$. This scale was then transferred to twenty-four Astrographic Regions in declination $-45^{\circ}$, each region being photographed on the same plate as the polar sequence.

Other sections, most of which contain one or more tables, deal with star counts, spectral types, mean colour index, faint stars of large proper motion, stars with large proper motion, motion of stars in general, the nearest stars, mean parallaxes. The Catalogue itself is preceded by a brief "Explanation", though the headings of the columns are generally sufficient to explain what follows.

* Catalogue of 20,554 Faint Stars in the Cape Astrographic Zone $-40^{\circ}$ to $-52^{\circ}$ for the Equinox of $1900^{\circ} 0$ giving Positions, Precessions, Proper Motions and Photographic Magnitudes derived from Photographs taken at the Royal Observatory, Cape of Good Hope, under the direction of Dr. H. Spencer Jones and Dr. J. Jackson; also Spectral Types classified from Plates at the Harvard College Observatory, Cambridge, Mass., U.S.A., by Miss Annie J. Cannon. Pp. Ivii + 414. (Lundon: H.M. Stationery Office, 1939.) 428. net.

\section{FORTHCOMING EVENTS}

[Meeting marked with an asterisk is open to the public.] THURSDAY, JULY 17

ROYAL Socrety (at Burlington House, Piccadilly, London, W.1), at 4.30 p.m.-Prof. W. W. C. Topley, F.R.S.: "On the Biology of Epidemics (Croonian Lecture).

FRIDAY, JULY 18

Institute of Physics (Manchester Branch) (in the Physics Department, University, Manchester), at 7, p.m.-Dr. H. Spencer Jones,

\section{APPOINTMENTS VACANT}

APPLICA TIONS are invited for the following appointments on or before the dates mentioned

DEPUTY DIRECTOR OF EDUCATION-The Director of Education' County Hall, Chichester (July 18).

LeCTURER IN Mathematics-The Acting Clerk to the Governors, South-East Essex Technical College, Longbridge Road, Dagenham, Essex (July 19).

Head of the School of Pharmacy-The Principal, college of Technology and Commerce, Leicester (July 21).

Demonstrator of Physiology aNd BIochemistry-The School Secretary, St. Mary's Hospital Medical School, London, W.2 (July 26).

\section{REPORTS AND OTHER PUBLICATIONS}

(not included in the monthly Books Supplement)

\section{Great Britain and Ireland}

Ministry of Agriculture and Fisheries. Bulletin No. 122 : Specifications and Methods of.Analysis for Tar Oil Winter Washes. Pp. iv +22 (London: H.M. Stationery Office.) 6d. net.

Home Office Circular 807624 (Board of Education Circular 1554) Juvenile Offences. Pp. 16. (London: H.M. Stationery Office.) $3 d$. net.

The Farmers' Club Library. A Classifled List of Books. Pp. 48 (London: 'The Farmers' Club.) A Classifled The College of the Pharmaceutical Society. Annual Report of Research Work, 1940. Pp. 30. (London: Pharmaceutical Society.) [196

University of St. Andrews: The Chair of Chemistry in the United College of St. Salvator and St. Leonard. Centenary Lecture, 6th Decem ber 1940. By Sir James Colquhoun Irvine. Pp. $27+6$ plates. (Edinburgh and London: Oliver and Boyd.)

\section{Other Countries}

U.S. Department of Agriculture. Farmers' Bulletin No. 1855 Culture, Disease and Pests of the Box Tree. By Freeman Weiss and L. G. Baumhofer. Pp. ii +18 . 5 cents. Farmers' Bulletin No. 1861 : Insect Pests of the Peach in the Eastern States. By Oliver I. Snapp. Pp. ii +34 . 10 cents. Miscellaneous Publication No. $369:$ The Mineral Composition of Crops with particular reference to the Soils in which they are Grown; a Review and Compilation. By Kenneth C. Beeson. Pp. 164. 20 cents. Technical Bulletin No. 762: Structure and Development of the Alimentary Canal of the Southern Armyworm Larva. my Panl A. Woke. Pp. 30 . 5 cents. (Washington, D.C. : Government By Panl A. Woke. Pp. 30. 5 cents. (Washington, D.C. : Government
Printing Office.)

Transactions of the San Diego Society of Natural History. Vol. 9, No. 25: The Paleontology and Stratigraphy of the Pleistocene at Signai Hill, Long Beach, California. By James H. DeLong, Jr. Pp. 229-252. Vol. 9, No. 26: A Key to the Pycnogonida of the Pacific Coast of North America. By Joel W. Hedgpeth. Pp. 253-264 (plates 9-11). Vol. 9, No. 27: The Distribution of Pocket Gophers in Southeastern California. By John E. Chattin. Pp. 265-284. Vol. 9, No. 28 : A New Chuckwalla from Santa Catalina Island, Gulf of California, Mexico. By Charles E. Shaw. Pp. 285-288. (San Diego, Calif. : San Diego Society of Natural History.)

Bernice P. Bishop Museum. Bulletin 161: The Hawaiian Planter. Vol 1: His Plants, Methods and Area of Cultivation. By E. S. Craig. hill Handy $\mathrm{Pp}$. iii $+227+8$ plates. Bulletin 162: Southern Lau, Fiji an Ethno raphy. By Tpu Thompson. Pp iii $208+5$ plates. Bulletin 166: Zonitid Snails from Pacific Islands, Parts 3 and 4 ; Bulletin 166: Zonitid Snails from Pacific Islands, Parts 3 and 4 ; 3: Genera other than Microcystinae ; 4 : Distribution and Indexes. By H. Burrington Baker. Pp. iii $+205-370+$ plates $43-65$. Bulletin 168: Oceanic, American Indian and African Myths of Snaring the Sun. By Katharine Luomala. Pp. 58. Bulletin 169: Geology of wland. $P$ p. 43+4 plates. (Honolulu: Bernice P. Bishop Museum.)

Editorial and Publishing Offices

MACMILLAN \& CO., LTD.

ST. MARTIN'S STREET, LONDON, W.C.2.

Telephone: Whitehall 8831 Telegraphic Address: Phusis Lesquare London Advertisements should be addressed to

T. G. Scott \& Son, Ltd., Three Gables, London Road, Merstham, Surrey Telephone: Merstham 316

The annual subscription rate is 64100 , payable in advance, Inland or Abroad All rights reserved. Registered as a Newspaper at the General Post Office. 